\title{
Quantitative capabilities of STXM to measure spatially resolved organic volume fractions of mixed organic / inorganic particles
}

\author{
Matthew Fraund ${ }^{1}$, Tim Park ${ }^{1}$, Lin Yao ${ }^{2}$, Daniel Bonanno ${ }^{1}$, Don Q. Pham ${ }^{1}$, and Ryan C. Moffet ${ }^{1, a}$ \\ ${ }^{1}$ Department of Chemistry, University of the Pacific, Stockton, CA 95211, USA \\ ${ }^{2}$ Department of Chemistry, Beijing Normal University, Beijing, 100875, China \\ a current address: Sonoma Technology, Petaluma, CA 94954, USA
}

Correspondence: Ryan C. Moffet (rmoffet@sonomatech.com)

Received: 4 October 2018 - Discussion started: 20 November 2018

Revised: 13 February 2019 - Accepted: 19 February 2019 - Published: 12 March 2019

\begin{abstract}
Scanning transmission X-ray microscopy coupled with near-edge X-ray absorption and fine structure (STXMNEXAFS) spectroscopy can be used to characterize the morphology and composition of aerosol particles. Here, two inorganic / organic systems are used to validate the calculation of organic volume fraction (OVF) and determine the level of associated error by using carbon K-edge STXM data at 278, 285.4, 288.6, and $320 \mathrm{eV}$. Using the mixture of sodium chloride and sucrose as one system and ammonium sulfate and sucrose as another, three solutions were made with $10: 1$, $1: 1$, and $1: 10$ mass ratios (inorganic to organic). The OVFs of the organic-rich aerosols of both systems deviated from the bulk OVF by less than $1 \%$, while the inorganic-rich aerosols deviated by approximately $1 \%$. Aerosols from the equal mass mixture deviated more (about $4 \%$ ) due to thick inorganic regions exceeding the linear range of Beer's law. These calculations were performed after checking the data for poor image alignment, defocusing issues, and particles too thick to be analyzed. The potential for systematic error in the OVF calculation was also tested by assuming the incorrect composition. There is a small (about $0.5 \%$ ) OVF difference if the organic is erroneously assumed to be adipic acid rather than the known organic, sucrose. A much larger difference (up to $25 \%$ ) is seen if sodium chloride is assumed instead of ammonium sulfate. These results show that the OVF calculations are fairly insensitive to the organic while being much more sensitive to the choice of inorganic.
\end{abstract}

\section{Introduction}

Atmospheric aerosols are airborne mixtures of solid and liquid phase components such as soot, inorganic salts, trace metals, and organics (Seinfeld and Pandis, 2006). These aerosols have been shown to cause detrimental health effects upon inhalation and can negatively impact visibility, especially around large cities (Villeneuve et al., 2002). In addition, aerosols currently represent the largest source of uncertainty in radiative forcing from anthropogenic sources according to the 2013 Intergovernmental Panel on Climate Change (IPCC) report (Stocker et al., 2013). Two of the main ways in which aerosols can affect radiative forcing are through aerosol-radiation interactions (also known as the "direct effect") and aerosol-cloud interactions (also known as the "indirect effect"). One of the limitations of the predictive power of global climate models is the dependence that aerosol-cloud interactions have on individual particle composition (Pöschl, 2005). Because the complex and varied compositions of aerosols are linked to their impacts on health and the environment, quantitative characterizations of detailed aerosol chemical and physical properties are necessary.

Many methods exist for quantifying the bulk composition of an aerosol sample both in real time (online) or offline. Offline analysis is most commonly achieved by analysis of filter sample deposits. Characterization with filter samples benefits from a large body of literature detailing standard operating procedures along with a variety of compatible analysis methods (Chow, 1995). Depending on the filter type and composition, a limited elemental analysis can be conducted using, for example, Proton-induced X-ray emission (PIXE) or in- 
ductively coupled plasma with atomic emission spectrophotometry (ICP-AES) (Artaxo et al., 1993; Menzel et al., 2002). While these methods are highly accurate and precise, they often cannot offer the possibility of quantifying the lighter elements $(\mathrm{C}, \mathrm{N}, \mathrm{O})$, which often make up the majority of the accumulation mode aerosol. Online bulk analysis is most often accomplished with relatively complex automated instruments. Thermo-optical analysis is regularly performed and has well-established protocols for quantitatively determining fractions of organic carbon (OC) and elemental carbon (EC) (Karanasiou et al., 2015). The aerosol mass spectrometer (AMS) and the related Aerosol Chemical Speciation Monitor (ACSM) are real-time instruments which can be operated in situ, allowing for aerosol events and plume evolution to be studied ( $\mathrm{Ng}$ et al., 2011). Heavier elements (Al and higher) can be measured in real time with a portable X-ray fluorescence spectrometer with low detection limits $\left(<40 \mathrm{ng} \mathrm{m}^{-3}\right)$ (Asano et al., 2017). Laser-induced breakdown spectroscopy (LIBS) is able to detect light and heavy elements down to low ppm levels in real time; however shot-to-shot variation hampers the quantitative capabilities of this technique (Hahn and Omenetto, 2012; Redoglio et al., 2018; Dudragne et al., 1998). Although many of these quantitative techniques have well-defined methods along with, in some sampling locations, long historical records, bulk measurements cannot easily study particle-specific qualities of aerosols.

The challenge of characterizing the composition and source variation within aerosol populations highlights the necessity for quantitative measurement techniques that can determine particle-resolved composition. Many of these techniques are also in situ and time resolved, like the Single Particle Soot Photometer (SP2), which measures black carbon and any associated coating by way of incandescence and scattering (Raatikainen et al., 2015; Baumgardner et al., 2004; Schwarz et al., 2006). Like its counterpart, the single-particle aerosol mass spectrometer (SP-AMS) can also provide in situ and time-resolved composition but it does so for individual particles (Canagaratna et al., 2007). Single-particle laser desorption instruments like the single-particle laser ablation time-of-flight (SPLAT) mass spectrometer and the aerosol time-of-flight mass spectrometer (ATOFMS) (Spencer and Prather, 2006; Zelenyuk and Imre, 2005; Healy et al., 2013) have been used to obtain particle information about particle composition. Other single-particle parameters of interest, like optical properties and particle density, are able to be calculated from ATOFMS data as well (Moffet and Prather, 2005). Online techniques like these provide useful size and composition information but cannot easily probe the detailed morphology, quantitative single-particle composition, or spatially resolved composition of aerosol particles; for this, microscopic and spectromicroscopic techniques may be better suited. Although microscopy measurements can carry more stipulations (substrate effects, Moffet et al., 2016; sample storage considerations, analysis time, and sometimes large infrastructure requirements), techniques like scanning elec- tron microscopy (SEM), transmission electron microscopy (TEM), atomic force microscopy (AFM), and scanning transmission X-ray microscopy (STXM) can distinguish and classify individual particles or regions therein based on morphology (Ault and Axson, 2016).

In addition to morphology, spectroscopic techniques can be combined with some types of microscopy to study particle composition. For example, high spatial resolution of TEM can be combined with both energy dispersive X-ray spectroscopy (EDX, also EDS) and electron energy loss spectroscopy (EELS) to obtain elemental information about internally mixed particles (Adachi and Buseck, 2008). Nanoscale secondary ion mass spectrometry (NanoSIMS) has also been applied to aerosol studies, often as a complementary technique to electron microscopy and EDX (Ghosal et al., 2014). This technique can be used to study carbonaceous aerosols (Li et al., 2016) as well as metal-rich aerosols (Li et al., 2017) and is able to provide composition as a function of depth. Another example of a combined spectromicroscopic technique is STXM, which can be coupled with near-edge Xray fine structure spectroscopy (STXM-NEXAFS). This retrieves quantitative elemental composition on a per-particle basis and is well suited for the analysis of $\mathrm{C}, \mathrm{N}$, and $\mathrm{O}$. With a spatial resolution of $\sim 30 \mathrm{~nm}$ and a spectral resolution of $\sim 150 \mathrm{meV}$ (Kilcoyne et al., 2003; Warwick et al., 2002), STXM can identify the elemental composition of distinct regions within a particle. From this (along with component density) an organic volume fraction (OVF) can be calculated, which can be used to characterize hygroscopicity and has been used in part to quantify the effects of biological activity of laboratory-generated sea-spray aerosols (Pham et al., 2017). Heavier elements can be difficult to measure in tandem with $\mathrm{C}, \mathrm{N}$, and $\mathrm{O}$ while using STXM, which has an energy operating range defined by the synchrotron and the design of the STXM. However, heavier elements such as $\mathrm{Na}$ and higher can be quantitatively measured using SEM coupled with EDX (Laskin et al., 2006). These two techniques have previously been used in combination on the same set of particles in order to retrieve an elemental composition that is both quantitative and includes lighter and heavier elements (Fraund et al., 2017; Piens et al., 2016).

The presence of an organic component within aerosol populations is important in determining their reactivity and hygroscopic behavior. The amount of organics and their distribution throughout an aerosol can affect the reaction rates and equilibrium positions of some heterogeneous reactions (Worsnop et al., 2002; Maria et al., 2004) Organics can also affect the ability of an aerosol to serve as both cloud condensation nuclei (CCN) or ice-nucleating particles (INP) (Cruz and Pandis, 1998; Möhler et al., 2008; Beydoun et al., 2017). Because of the vital role that organics play in affecting aerosol behavior, specifically the effects organics have in changing aerosol hygroscopicity, the OVF is used as a key piece of data feeding into $\kappa$-Köhler theory (Petters and Kreidenweis, 2007). The use of STXM to spatially 
resolve carbon species in aerosols has been reported since the early 2000s (Russell et al., 2002; Kilcoyne et al., 2003). An automated method for producing spatial maps of these aerosol components was presented in 2010 (Moffet et al., 2010). The method was further refined in 2016 (Moffet et al., 2016), where the use of carbon maps with only four energies was introduced to increase the number of particles analyzed, thereby improving particle population statistics. The quantitative capabilities of this four-energy mapping method are discussed in the current work by comparing the experimentally determined OVFs of two known solutions. Also discussed are the quality control measures necessary to ensure quantitative data, along with the potential for error should they be omitted. Lastly, the uncertainty introduced from assumptions made during OVF calculations was examined. To accomplish this, two systems of inorganic and organic mixtures were studied, each with three formulations of differing inorganic to organic ratios.

\section{Materials and methods}

\subsection{Standard preparation}

Standard $100 \mathrm{~mL}$ solutions of $\mathrm{NaCl} /$ sucrose and $\left(\mathrm{NH}_{4}\right)_{2} \mathrm{SO}_{4}$ /sucrose mixtures were prepared according to Table 1. Standard-grade (Sigma-Aldrich, $>99 \%$ purity) material was weighed using a recently calibrated analytical balance (Torbal, AGN200C) with an accuracy of $\pm 0.0001 \mathrm{~g}$. The powder was quantitatively transferred into a $100 \mathrm{~mL}$ volumetric flask $( \pm 0.1 \mathrm{~mL})$, which was then filled with room-temperature Millipore-filtered $18 \mathrm{M} \Omega$ distilled water, capped, and inverted to mix. All glassware and utensils were washed and soaked in a nitric acid bath overnight before use.

\subsection{Sample production and collection}

After the solutions were prepared, the aerosol generation apparatus in Fig. 1 was assembled. Nitrogen gas at $\sim 20$ PSI $(\sim 140 \mathrm{kPa})$ was fed into a Collison nebulizer ( 3 jet MRE, $\mathrm{CH}$ Technologies USA) which was filled with one of the standard solutions. The aerosols first passed through an Erlenmeyer flask with a rubber stopper and two stainless steel pieces of tubing in order to collect any large droplets that may have been produced. This flask also had a HEPA-filtered air inlet in order to maintain atmospheric pressure and airflow rate. The still-humid aerosols next pass through two $66 \mathrm{~cm}$ long laboratory-made diffusion driers. The driers consist of a mesh cylinder ( $2 \mathrm{~cm} \mathrm{OD)} \mathrm{surrounded} \mathrm{by} \mathrm{a} \mathrm{larger}$ Plexiglas cylinder $(9 \mathrm{~cm}$ OD) with the space between the tubes filled with desiccant (Silica Gel). The dried aerosols are finally directed into a small 4-stage collision impactor (Sioutas Personal Cascade Impactor \#225-370, SKC, Fullerton, CA USA), which was loaded with $\mathrm{Si}_{3} \mathrm{~N}_{4}$ windows to collect the particles. The four stages had $\mathrm{D}_{50}$ size cuts at 2.5, $1.0,0.5$, and $0.25 \mu \mathrm{m}$. A small diaphragm vacuum pump was

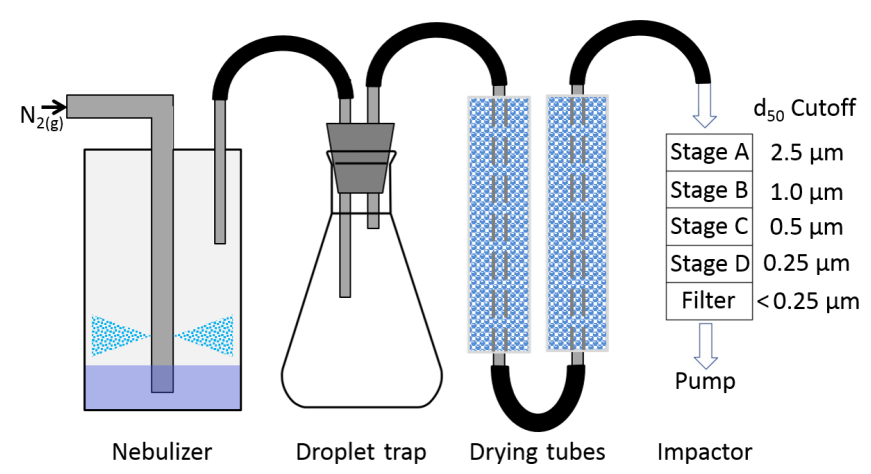

Figure 1. Schematic of the aerosol generation setup used to nebulize, dry, and collect the lab-generated aerosols. Running through the drying tubes are smaller mesh tubes surrounded by silica gel desiccant (represented in blue).

attached to the bottom of the impactor to maintain an airflow of $\sim 9 \mathrm{~L} \mathrm{~min}^{-1}$.

\subsection{STXM-NEXAFS data collection and analysis}

$\mathrm{Si}_{3} \mathrm{~N}_{4}$ windows were mounted to an aluminum plate (Kilcoyne et al., 2003) to be imaged at the STXM beamline 5.3.2.2 at the Advanced Light Source (ALS, Berkeley, CA, USA) as well as at the Canadian Light Source (CLS, Saskatoon, SK, Canada). These STXM beamlines have an energy range of 250-780 eV (ALS) and 130-2700 eV (CLS), which allows for the $\mathrm{C}$ K-edge to be studied. Soft X-rays were energy selected and then focused to a $\sim 30 \mathrm{~nm}$ spot size on the sample surface. A $15 \times 15 \mu \mathrm{m}$ region containing individual particles was then selected and the sample stage was raster scanned using $40 \mathrm{~nm}$ steps. This process was repeated at four different energies: Pre- and post-edge images were taken along with an additional two images for $\mathrm{C}$ to allow for regions of soot, inorganics, and organics to be determined. The four energies near the carbon edge corresponded to the pre-edge, $\mathrm{C}=\mathrm{C}, \mathrm{COOH}$, and post-edge regions $(278,285.4$, 288.6 , and $320 \mathrm{eV}$ ). These raw data are available in a public data repository (Fraund, 2019).

These groups of images (collectively called a "stack") are first aligned with a method based on Guizar-Sicarios' image registration algorithm (Guizar-Sicairos et al., 2008); this ensures particle positions are constant throughout the stack. Once the stack is aligned, a gamma correction (Reinhard et al., 2010) is applied with the normalized intensity of each pixel being raised to an exponent (a $\gamma$ of 15 is used here) to modify the image contrast in order to detect small, faint particles. Otsu's method is then applied to this enhanced image, which automatically differentiates between particles and background (Otsu, 1975). The intensity image is then transformed into an optical density (OD) image on a per-pixel ba- 
Table 1. Calculated masses of each compound needed to make $100 \mathrm{~mL}$ of solution. Measured masses in parentheses.

\begin{tabular}{lr|rr}
\hline \multicolumn{1}{c}{ System } & & Inorganic $(\mathrm{g})$ & Organic $(\mathrm{g})$ \\
\hline Sodium chloride / sucrose & $10: 1$ & $1.5213(1.5210)$ & $0.1521(0.1523)$ \\
& $1: 1$ & $0.7327(0.7325)$ & $0.7327(0.7328)$ \\
& $1: 10$ & $0.1185(0.1185)$ & $1.1848(1.1846)$ \\
\hline Ammonium sulfate / sucrose & $10: 1$ & $1.2742(1.2748)$ & $0.1274(0.1273)$ \\
& $1: 1$ & $0.6701(0.6701)$ & $0.6701(0.6701)$ \\
& $1: 10$ & $0.1167(0.1165)$ & $1.1672(1.1673)$ \\
\hline
\end{tabular}

sis using the following:

$\mathrm{OD}=-\ln \left(\frac{I}{I_{\mathrm{O}}}\right)=\mu \rho t$,

where OD is optical density, $I$ is the intensity of the given pixel, and $I_{\mathrm{o}}$ is the background intensity, with $\mu$ being the mass absorption coefficient, $\rho$ being the density, and $t$ being the thickness of the given pixel.

The additional carbon edge images were used to determine carbon speciation according to previously developed algorithms (Moffet et al., 2010). With this algorithm, a series of thresholds are used to identify inorganic- and organicdominant regions of each particle. These regions are differentiated based on their pre- to post-edge ratio $\mathrm{OD}_{278} / \mathrm{OD}_{320}$. Previous work has compared this pre- to post-edge ratio with the calculated thickness ratios of adipic acid and various inorganics. A pre- to post-edge ratio of 0.5 was selected as a general thresholding value when the identity of the inorganic is not known (Moffet et al., 2010).

Carbon edge images were also used to calculate an organic volume fraction (OVF). This was done by first calculating the thicknesses of both the inorganic and organic components using a previously published method (O'Brien et al., 2015), which is reproduced here. Knowing that the OD at each pixel is due to a mixture of inorganic and organic components, the following equations can be written:

$\mathrm{OD}_{278}=\mu_{278}^{\mathrm{I}} \rho^{\mathrm{I}} t^{\mathrm{I}}+\mu_{278}^{\mathrm{O}} \rho^{\mathrm{O}} t^{\mathrm{O}}$
$\mathrm{OD}_{320}=\mu_{320}^{\mathrm{I}} \rho^{\mathrm{I}} t^{\mathrm{I}}+\mu_{320}^{\mathrm{O}} \rho^{\mathrm{O}} t^{\mathrm{O}}$

with $\mathrm{OD}_{\mathrm{E}}$ being the optical density at energy $\mathrm{E}$ (either 278 or 320 ), and I and O representing inorganic and organic components. The elemental mass absorption coefficients used here have been retrieved from previously published work (Henke et al., 1993). By calculating and rearranging $\mathrm{OD}_{320}-\mathrm{OD}_{278}$ (taking $X^{\mathrm{I}}=\mu_{320}^{\mathrm{I}} / \mu_{278}^{\mathrm{I}}$ for convenience), the thicknesses of the inorganic and organic components can be expressed as follows:

$$
\begin{aligned}
t^{\mathrm{O}} & =\frac{\mathrm{OD}_{320}-X^{\mathrm{I}} \mathrm{OD}_{278}}{\left(\mu_{320}^{\mathrm{O}}-X^{\mathrm{I}} \mu_{278}^{\mathrm{O}}\right) \rho^{\mathrm{O}}} \\
t^{\mathrm{I}} & =\frac{\mathrm{OD}_{278}-\mu_{278}^{\mathrm{O}} \rho^{\mathrm{O}} t^{\mathrm{O}}}{\mu_{278}^{\mathrm{I}} \rho^{\mathrm{I}}},
\end{aligned}
$$

Mass absorption coefficients were calculated in accordance with published methods (Henke et al., 1993). The densities of sucrose $\left(1.59 \mathrm{~g} \mathrm{~cm}^{-3}\right), \mathrm{NaCl}\left(2.16 \mathrm{~g} \mathrm{~cm}^{-3}\right)$, and $\left(\mathrm{NH}_{4}\right)_{2} \mathrm{SO}_{4}$ $\left(1.77 \mathrm{~g} \mathrm{~cm}^{-3}\right)$ are used in this work. This study takes advantage of the a priori knowledge of the inorganic and organic compounds. For the sodium chloride / sucrose system, the mass absorption cross sections for sodium chloride and sucrose are calculated and their known densities are used for calculations. The same thing is done for the ammonium sulfate / sucrose system. Inorganic, organic, and total thickness maps can then be generated, and the OVF for each pixel (or each particle) can be calculated by taking the ratio of organic thickness to total thickness as shown in Fig. 2.

\subsection{Quality control of processed images}

In order to ensure quantitative results from this analysis, each data set was screened for any systematic errors that may have occurred during collection or analysis. The first screening step is to remove stacks with defocusing issues, which means that the errors in the zone plate stage positioning result in a sample image that is not in focus. These defocusing issues occurred due to long-term wear on the zone plate translation stage. When the sample is not at the focal point of the incoming X-rays, this increases the minimum spatial resolution of the instrument. This also results in unreliable particle morphologies, with many particles taking on a characteristic toroidal or donut shape, often seen in unfocused images. Along with major focusing issues, image stacks with a single, slightly defocused image must also be avoided. Field of views (FOVs) with a single defocused image can present errors in mass determination and $\mathrm{C}$ species identification (soot, organic, or inorganic). This is especially apparent near the edges of particles or inorganic cores where defocusing can blur these edges and, for example, misattribute inorganic pixels within an organic coating. 

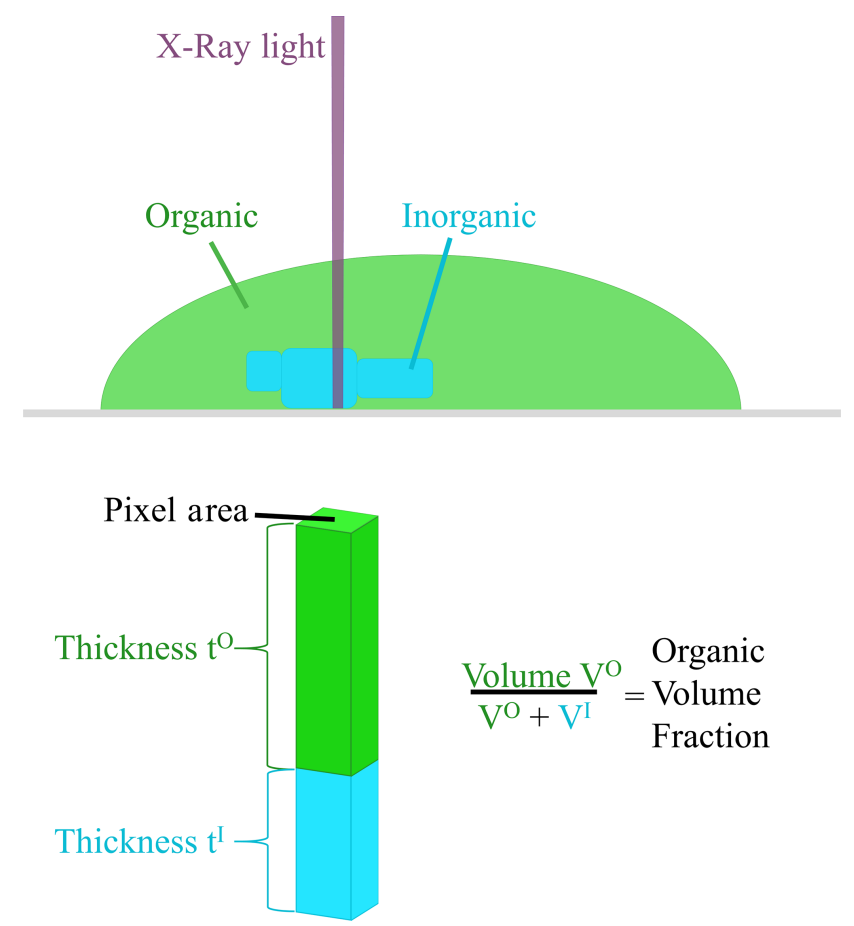

Figure 2. Visual of organic volume fraction (OVF) calculation with $2 \mu \mathrm{m}$ particle and $30 \mathrm{~nm}$ spot size.

Following this, stacks were reviewed for proper alignment. This was checked by overlaying the aligned images and highlighting pixels which did not match. Any misalignment found was corrected manually before undergoing automatic particle detection.

The image adjustment done on stacks prior to particle detection can introduce errors. On particularly noisy data, a high gamma correction value can accentuate noise peaks, causing them to be erroneously labeled as particles, often being only a few pixels wide. Gamma corrections which are too low can also cause the thinner, outer regions of particles to be ignored, instead only detecting the relatively thicker particle cores. Because of this, each FOV was visually inspected for correct particle detection and the gamma correction was adjusted accordingly between $5 \leq \gamma \leq 15$. In addition, a filter was applied after particles are detected, which discounts any particles less than 8 contiguous pixels. Detected particles which were cut off by the edge of the image frame were also removed from analysis. An exception was made for particles for which only a small portion (less than 8 pixels) appeared to be out of the frame, which were identified manually. These particles were not removed in order to improve particle statistics at the expense of a small error in accuracy.

A final correction was made on any pixels which had an OD $>1.5$, which is outside of the linear range of Beer's law, where Eq. (1) is no longer valid (Moffet et al., 2011; Wen et al., 2014; Bourdelle et al., 2013). These pixels are from thick or dense regions of the particle, often being from the parti- cle's inorganic center. Because the high-OD regions tend to be inorganic cores, and due to the prevalence of cubic $\mathrm{NaCl}$ crystals in atmospheric aerosols, the regions are treated by taking the thickness to be equal to the lateral dimension of a cube having the same area as the high-OD areas. The number of pixels with an OD $>1.5$ are added up and the square root of the sum is taken. This is then multiplied by the pixel width and the result is used as the particle thickness for all $\mathrm{OD}>1.5$ pixels.

\section{Results and discussion}

\subsection{Particle morphology}

Particle mixing state and morphology can potentially impact their effectiveness as either ice nuclei or CCN (Baustian et al., 2012, 2013; Pöschl et al., 2010; DeMott et al., 2003). Here, particles were produced by nebulization of mixed organic / inorganic solutions of known concentrations. Because each of the solutes are quite soluble in water (with solubilities of $75.4 \mathrm{~g} / 100 \mathrm{~mL}, 35.9 \mathrm{~g} / 100 \mathrm{~mL}$, and $201.9 \mathrm{~g} / 100 \mathrm{~mL}$ for ammonium sulfate, sodium chloride, and sucrose) (Haynes, 2014) and because the nebulization process ensures a well-mixed solution, the resulting droplets are expected to be similar in composition to the homogenous bulk solution and therefore little particle-to-particle variability is anticipated. When qualitatively comparing OVFs and carbon speciation maps, most samples exhibited a core-shell morphology that is common in mixed inorganic/organic systems (Shiraiwa et al., 2013; Veghte et al., 2013). A few representative pairs of the sodium chloride / sucrose and ammonium sulfate / sucrose systems are shown in Figs. 3 and 4.

\subsubsection{Sodium chloride / sucrose morphology}

For the sodium chloride / sucrose system, across all stages the inorganic-rich mixture showed cubic particles with few organic-dominant regions according to the $\mathrm{C}$-speciation map. In the OVF maps, like the one shown in Fig. 3, a thin coating of organics can be seen surrounding the inorganic centers. This thin coating of organics is not visible in the $\mathrm{C}$-speciation map due to the thresholding of the pre- to post-edge ratio for all pixels exceeding 0.5 as described above. Particles appear to be made up of multiple smaller cubic units, which is consistent with scanning electron microscopy images of labgenerated sodium chloride aerosols (Karagulian et al., 2008).

A similar observation can be made for the 1:1 mixture, except with a thicker coating of organics. Of note here is the ability to resolve multiple individual $\mathrm{NaCl}$ crystals within some of the aerosols when looking at the OVF maps. Particles collected from the smallest stage (stage D, not shown) can still be seen as an inorganic core with an organic coating in the OVF maps, although this is no longer apparent from the $\mathrm{C}$-speciation maps. A few of the particles appear not 


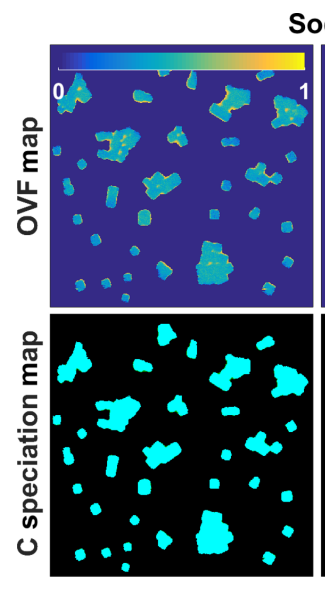

$10: 1$
Sodium chloride/sucrose

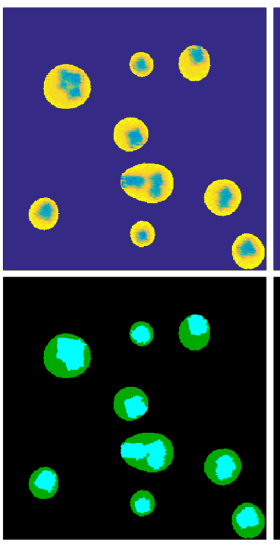

$1: 1$

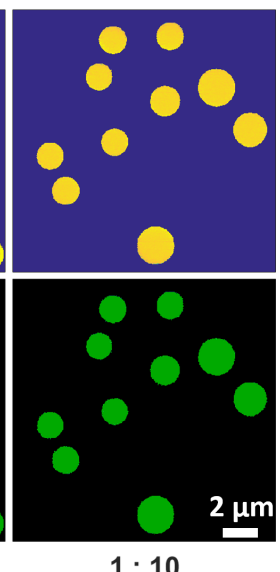

$1: 10$

Figure 3. Representative organic volume fraction (OVF) maps and C-speciation maps for the sodium chloride / sucrose system. Samples shown were collected from impactor stage $C(0.5-0.25 \mu \mathrm{m}$ nominal size range). For the $\mathrm{C}$-speciation maps, green represents organic-dominant regions and blue represents inorganic-dominant regions.

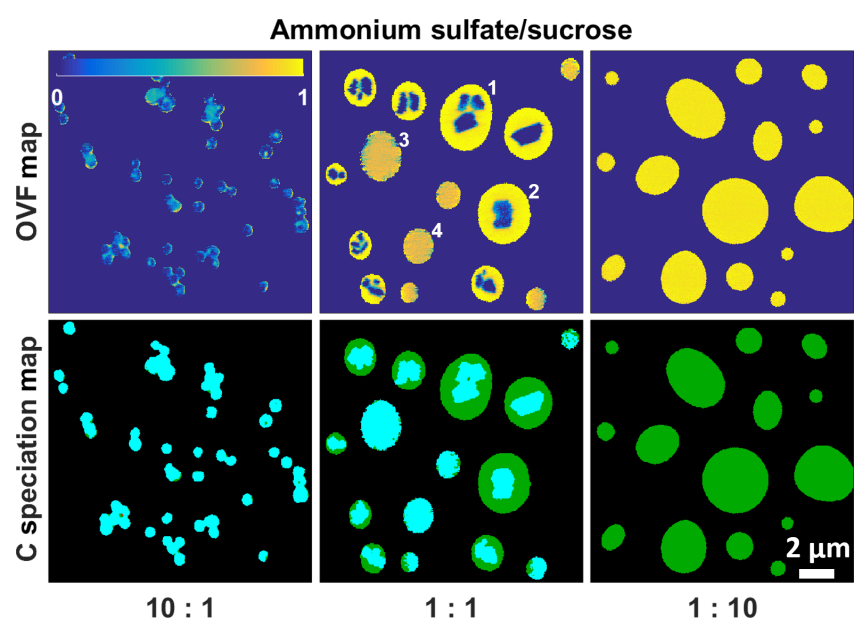

Figure 4. Representative organic volume fraction (OVF) maps and C-speciation maps for the ammonium sulfate/sucrose systems. Samples shown were collected from impactor stage C $(0.5-0.25 \mu \mathrm{m}$ nominal size range). For the $\mathrm{C}$-speciation maps, green represents organic-dominant regions and blue represents inorganic-dominant regions. The four particles labeled in the top middle image have OVFs of $0.56,0.41,0.77$, and 0.79 for particles labeled $1,2,3$, and 4.

to exhibit a core-shell morphology but instead look partially engulfed, which is observed for inorganic / organic mixtures under certain conditions (Kwamena et al., 2010). However, this may well be a result of impaction and so it is difficult to comment on how these particles look when airborne.

OVF maps and C-speciation maps for the organic-rich mixture show circular homogenous particles over all stages. No NaCl-dominant inclusions or particles were observed,

though some inorganic material was detected based on the pre-edge absorption. From the OVF map in Fig. 3, the inorganic phase present is homogenously mixed with the organic phase in this system. Previous studies have shown that high organic concentrations can inhibit the crystallization of inorganic species (Bodsworth et al., 2010; Choi and Chan, 2002).

\subsubsection{Ammonium sulfate / sucrose morphology}

In contrast to the sodium chloride/sucrose system, the inorganic-rich mixture for the ammonium sulfate / sucrose system did not show cubic crystals. Instead, circular inorganic particles were observed at all stages. Ammonium sulfate particles have been observed with a circular or rounded shape by TEM at these sizes before (Pósfai et al., 1998; Buseck and Posfai, 1999). Pósfai et al. suggested that the ammonium sulfate started forming as a polycrystalline solid but then recrystallized. Most of the ammonium sulfate particles observed by Pósfai et al. were rounded and, although some particles were aggregates, selected-area diffraction (SAED) patterns indicated most were single crystals. In addition, a bumpy irregular surface was documented. Buseck et al. showed how ambient ammonium sulfate particles had a coating of organics which filled in these bumps and irregularities. From the OVF maps in Fig. 4 of the current work, a thin coating of organics can be seen in most particles, along with a few particles which show a higher-than-average OVF.

The 1:1 ammonium sulfate / sucrose mixture presented two distinct particle types, seen in both OVFs and Cspeciation maps. A core-shell type of particle is most commonly observed with a defined, rectangular inorganic core surrounded by a thick organic coating. Also seen are circular, fairly homogenous particles which have a pre- to postedge ratio $>0.5$ according to the $\mathrm{C}$-speciation map. The OVF map, however, shows that around $75 \%$ of the volume of these particles are attributed to the organic component. This phase separation is discussed in further detail below.

The organic-rich mixture of ammonium sulfate and sucrose shows the same behavior as the sodium chloride / sucrose system, with homogenous organic-dominant particles. This, as well, is likely attributed to the inhibition of crystallization in concentrated organic solutions. The lack of efflorescence, even at low relative humidity, has been previously observed for ammonium sulfate / organic mixed aerosols with an organic $\mathrm{O}: \mathrm{C}$ ratio $>0.7$ and organic : sulfate mass ratios above 2 (Bertram et al., 2011). In this study, the lack of efflorescence was seen with an organic: sulfate mass ratio of $10: 1$ and so, with an $\mathrm{O}: \mathrm{C}$ ratio of 0.91 , so this system should be governed by the same principles.

\subsubsection{Multiple inorganic inclusions}

For the inorganic-rich and $1: 1$ systems, multiple distinct inorganic inclusions can be seen within individual particles. 
This may be a result of using the relatively viscous sucrose as the organic component. A similar diffusion dryer setup to the one shown in Fig. 1 has been studied previously and is reported to dry at a rate of $\sim 99.7 \% \mathrm{RH} \mathrm{s}^{-1}$ (Veghte et al., 2013). As a droplet of solution begins to rapidly dry while passing through the dryers, its viscosity increases. By becoming increasingly viscous, mass transfer of components within the particle is inhibited (Tong et al., 2011; Bones et al., 2012). Upon reaching a low enough water activity, spontaneous nucleation of the inorganic component begins but diffusion of additional inorganics is hampered by the viscous droplet. As drying continues, more nucleation centers form and crystallize before they are able to combine into a single inorganic core. The formation of single or multiple inorganic inclusions as a result of drying rate has been observed before in less viscous organic / inorganic systems (Fard et al., 2017).

\subsection{Accuracy of single-particle organic volume fractions}

Experimental per-particle OVFs for each system and mixture were averaged over all stages and compared with the theoretical OVFs in Fig. 5 and in Table 2. Values for organic mass fractions (OMFs) are included as well for completeness sake and for discussion in Sect. 3.3 below. The bulk OVF values were calculated using the composition of the bulk solution from which the particles were generated. For the sodium chloride / sucrose system, the experimental OVFs were underestimated compared to theoretical OVFs in all except the inorganic-rich mixture, which was overestimated. The experimental OVFs for the ammonium sulfate / sucrose mixture are all underestimated as well.

\subsection{1 $1: 1$ systems}

The largest deviation of the experimental OVF from the OVF calculated from the bulk solution was observed with $1: 1$ mixtures for both the sodium chloride / sucrose and ammonium sulfate / sucrose systems. Both of these systems were underestimated for similar reasons. Aerosols in both samples contained thick inorganic inclusions surrounded by organics (see Figs. 3 and 4). Many of these thick inorganic crystals were thick enough for their OD to exceed the linear range of Beer-Lambert law (OD > 1.5) and so the correction mentioned above was applied. However, considering that these cores are surrounded by a layer of organics, there is likely a layer above and below which the high-OD correction does not account for. This will lower the apparent volume of organics in those regions and decrease the particle's overall OVF value.

\subsubsection{Inorganic-rich systems}

The inorganic-rich systems for both the sodium chloride / sucrose and the ammonium sulfate / sucrose mixture

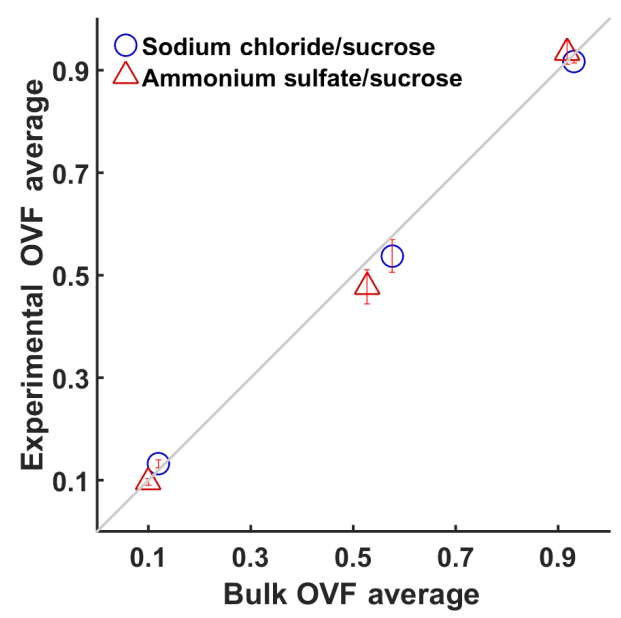

Figure 5. Correlation between experimentally determined average OVFs and calculated average OVFs for the sodium chloride / sucrose (blue circles) and ammonium sulfate / sucrose (red triangles) systems. A 1:1 line is shown in gray. Error bars represent standard error calculated by $\mathrm{SE}=(1.96 \cdot S) /\left(N^{1 / 2}\right)$, where $S$ is the standard deviation, $N$ is the number of particles, and 1.96 is the approximate number of standard deviations encompassing the central $95 \%$ of a student's $t$ distribution (Skoog et al., 2007). Error in bulk OVF is too small to be shown.

were slightly overestimated ( 0.012 and 0.009 , from Table 2$)$. This overestimation may be due to some amount of defocusing, especially in the pre-edge image. Images which were obviously defocused exhibited OVFs much higher (>30\% higher for the inorganic systems) than well-focused images and were excluded from analysis; however, images with subtler defocusing may still be present. Any defocusing present in the pre-edge images will result in depression of the measured OD, especially around the particle edges. Equation (4) shows that a decreased pre-edge OD will also increase the calculated organic thickness and therefore the OVF as well. As for the potential effects of the high-OD correction, while sodium chloride crystals which exceeded $1.5 \mathrm{OD}$ were present, the organic coatings observed are very thin, making this a minor issue. Instead, if the high-OD correction underestimated the thickness of inorganics present, this could also contribute to the overestimation in OVF for the sodium chloride / sucrose system. Another possible contribution to the slightly high OVF is if any carbonate was incorporated in the standard solutions during nebulization, as this ion will contribute to the carbon post-edge value, which was assumed to be dependent only on organics. Carbonate picked up from dissolved $\mathrm{CO}_{2}$, however, would only amount to approximately $1 \times 10^{-5} \mathrm{~g}$ in the $100 \mathrm{~mL}$ jar, which would correspond to an erroneous OVF increase of about $0.0005 \%$ and so the contribution is negligible (Greenwood and Earnshaw, 2012). The overestimation in the ammonium sulfate / sucrose system was smaller and, unlike with the sodium chloride / sucrose system, was within the margin of 
Table 2. Experimental and bulk values for organic volume fraction and organic mass fraction along with their associated absolute error (Relative errors for OVF and OMF are identical to within rounding). Errors with an asterisk cannot be attributed to statistics (95\% confidence) alone.

\begin{tabular}{clrrrrrrrr}
\hline & & Fields of & \multicolumn{2}{c}{ Organic volume fraction } & \multicolumn{3}{c}{ Organic mass fraction } \\
\cline { 5 - 9 } System & & view & Experimental & Bulk & Error & Experimental & Bulk & Error \\
\hline \multirow{2}{*}{ Sodium chloride / sucrose } & Inorganic rich & 6 & 0.132 & 0.120 & $0.012^{*}$ & 0.100 & 0.091 & $0.009^{*}$ \\
& $1: 1$ & 3 & 0.538 & 0.576 & $0.039^{*}$ & 0.467 & 0.500 & $0.033^{*}$ \\
& Organic rich & 3 & 0.923 & 0.931 & 0.009 & 0.900 & 0.909 & 0.009 \\
\hline \multirow{2}{*}{ Ammonium sulfate / sucrose } & Inorganic rich & 4 & 0.091 & 0.100 & 0.009 & 0.082 & 0.091 & 0.009 \\
& $1: 1$ & 11 & 0.571 & 0.527 & $0.044^{*}$ & 0.542 & 0.500 & $0.042^{*}$ \\
& Organic rich & 6 & 0.926 & 0.918 & 0.008 & 0.917 & 0.909 & 0.008 \\
\hline
\end{tabular}

statistical error. The inorganic-rich ammonium sulfate system also did not have any issues with thick inorganic regions, making it a fairly well-behaved system for STXM analysis. While the decrease in optical thickness of the ammonium sulfate particles compared to the sodium chloride particles could be due to differences in physical height, this is difficult to know given 2-dimensional images. However, the absorption cross section for ammonium sulfate is lower than the cross section for sodium chloride by a factor of 0.35 (Henke et al., 1993), which accounts for most of the difference in optical thickness.

\subsubsection{Organic-rich systems}

As shown in Table 2, the average OVF values for the organic-rich systems are in good agreement with their bulk OVF values, having an error of 0.009 for the sodium chloride / sucrose system and an error of 0.008 for the ammonium sulfate / sucrose system. These errors are the lowest for their respective inorganic / organic systems. Because OVF is calculated using STXM images collected before and after the $\mathrm{C}$-absorption edge, it is most sensitive to $\mathrm{C}$-containing compounds. In addition, three of the four $\mathrm{C}$-edge energies taken were associated with organics. Because of this, organic-rich particles may have better defined edges relative to inorganic particles when particle detection is performed. The OVF calculation is thus well suited to organic-rich particles like these and because of this, the error in experimental OVF fell within the bounds of statistical uncertainty.

\subsubsection{Phase separation in $1: 1$ ammonium sulfate / sucrose system}

For the 1:1 ammonium sulfate / sucrose system seen in Fig. 4, two particle types were observed: particles with a core-shell morphology where the organic regions surround a distinct inorganic core, and homogenous particles where a relatively constant OVF was observed. The presence of both phase-separated and homogenous particles was observed only for the $1: 1$ ammonium sulfate / sucrose system and was observed across all size ranges. Figure 6 highlights this system as unique compared to the others studied here.

The distribution of OVF values for most systems were Gaussian and centered around the bulk OVF value. The organic-rich systems showed little spread due to STXM's sensitivity to carbon. Both inorganic-rich systems had wider distributions and the 1:1 systems showed the widest OVF distributions. One issue that can plague particles with crystalline regions is that upon impaction with the substrate the particle can shatter (Mouri and Okada, 1993). Shattering involves small pieces of the particle breaking away, potentially removing organic and inorganic mass from the main particle in difficult-to-predict ratios. While we do not see small fragments distributed among larger ones, small-particle fragments are observed in the lowest stage. This may be due to the shattered fragments bouncing upon formation and traveling further down the impactor. The $1: 1$ ammonium sulfate / sucrose system, however, shows far more spread than any of the others due to the two particle types observed in this system.

This distinction between phase-separated particles and homogenous ones has been observed before, when mixed ammonium sulfate/ polyethylene glycol-400 particles generated from an aqueous solution are quickly dried before collection (Altaf and Freedman, 2017). Some of the particles studied were dried so quickly that a fraction of them were observed to solidify into an amorphous phase rather than nucleate a distinct crystalline phase. Because the diffusion drier setup described in the experimental section for the current work is drying particles at a similar rate compared to the rate discussed in Altaf et al. (2017), the same two types of particles were observed.

A size-dependent trend was also present in the $1: 1 \mathrm{am}-$ monium sulfate / sucrose system, with the homogenous particles tending to be smaller on average than the phaseseparated ones (see Fig. 7). This behavior was previously observed by Altaf et al. (2016), using an ammonium sulfate / Polyethylene glycol mixture. They observed that, depending on the inorganic / organic ratio, the inorganic compound could start to undergo spinodal rather than binodal 

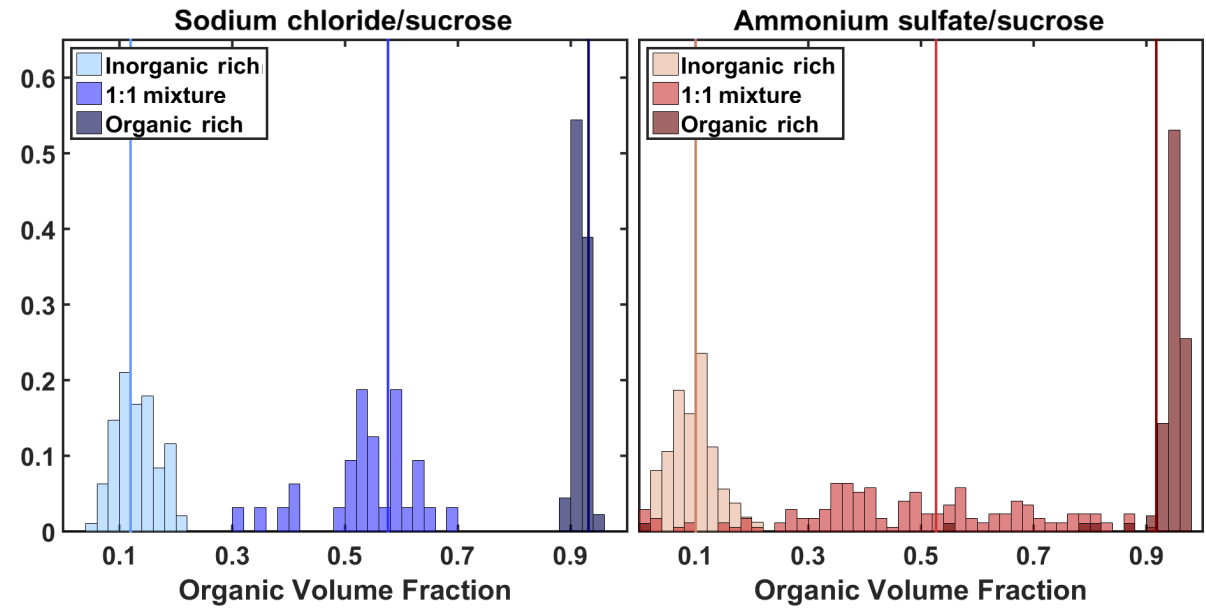

Figure 6. Organic volume fraction (OVF) histograms of both sodium chloride / sucrose (blue) and ammonium sulfate / sucrose (red) systems. The three mass ratios, $10: 1$ (inorganic rich), $1: 1$, and $1: 10$ (organic rich), are shown in different shades of color. The vertical line represents the bulk OVF value.

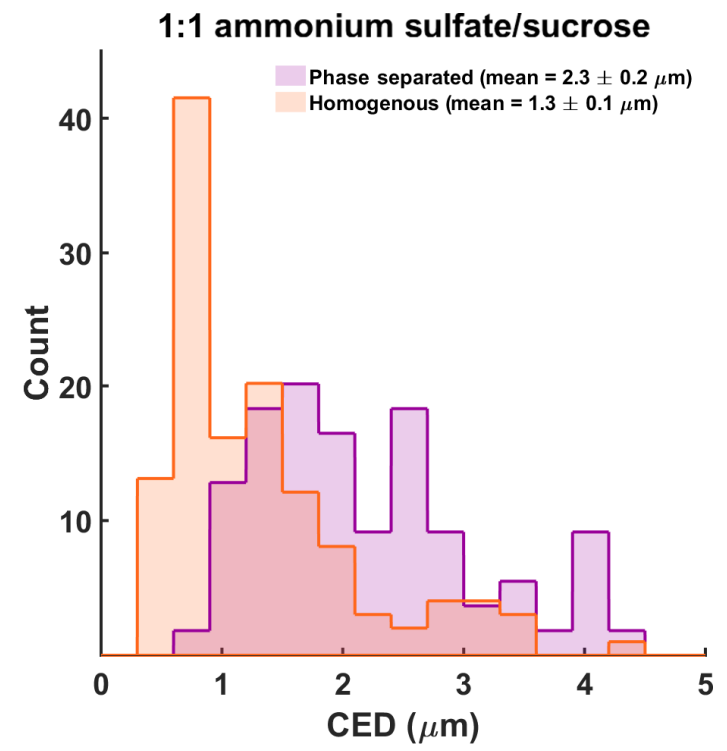

Figure 7. Circular equivalent diameter (CED, also called area equivalent diameter) histogram of homogenous and phase-separated particles, showing that homogenous particles tended to be smaller than phase-separated ones. Particles from stages B, C, and D are included here $(2.5-0.25 \mu \mathrm{m})$.

crystallization. The end result was a size dependence seen in certain inorganic / organic mass ratios, where nucleation of a separate phase became more energetically unfavorable at smaller sizes (Altaf et al., 2016).

The size distributions discussed in Altaf et al. (2016) and Altaf and Freedman, 2017 are on the order of 200 nm, about a factor of 10 smaller than the size distributions observed here. The increase in viscosity from using sucrose as an organic rather than polyethylene glycol may increase the sizes at which phase-separated and homogenous particles overlap.
It was noted in Altaf et al. (2016) that the components within smaller viscous particles may not have enough time to coalesce into a completely phase-separated particle. In addition, rapid drying may also result in the formation of an inorganic shell as the surface of a particle dries without water within the particle able to spread outward fast enough for very viscous particles (Tong et al., 2011).

The presence of two particle types (homogenous and phase separated) do not alone account for the spread of OVFs seen in Fig. 6 for the $1: 1$ ammonium sulfate / sucrose system. Although both types of particle are formed from the same bulk solution, and so are assumed to have the same composition, two competing issues in their analysis serve to broaden their OVF distribution. For the phase-separated particles, the issue of thick central regions persists. Because the high-OD correction may discount any organic coatings found above or below these regions and so the OVF will be depressed for these particles, this is shown in Supplement Fig. S1, where all of the high-OD particles are found below the bulk OVF value. Figure $\mathrm{S} 2$ shows a related idea, where all of the phaseseparated particles are found below the bulk OVF value because the phase-separated particles tend to be the ones with thick inorganic regions. For homogenous particles, having the inorganics distributed throughout the particle rather than concentrated in a core could result in some regions where the inorganics were poorly characterized, thereby raising the OVF. For instance, if any inorganic regions were located near the edge of the particle, the particle detection algorithm could exclude them due to having only one STXM image associated with inorganics. As mentioned above, because the organic components have three images (some with strongly absorbing transitions), organic regions near the particle edge are more likely to be better defined. The homogenous particles in Fig. 4 with rough edges and low OVF point to this. 


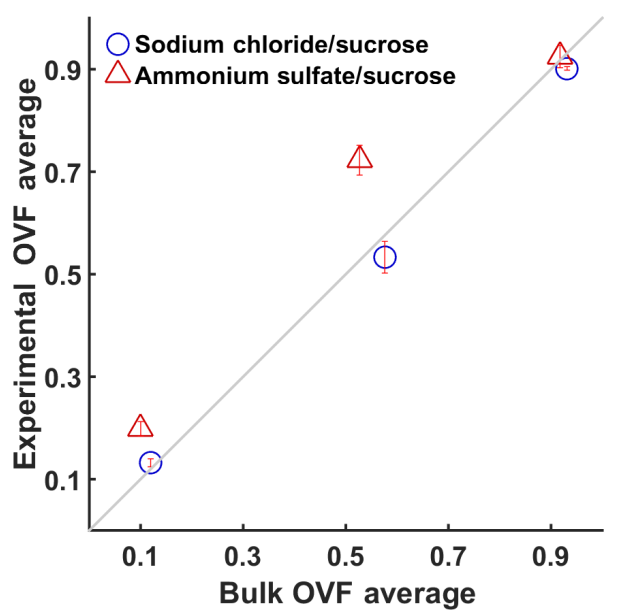

Figure 8. Correlation between experimentally determined and bulk OVF averages using sodium chloride and adipic acid as the assumed inorganic and organic, respectively.

Much of the extreme spread seen in the $1: 1$ ammonium sulfate / sucrose system, however, is due to the smallest stage (stage D, 0.5-0.25 $\mu \mathrm{m}$ ). Figure $\mathrm{S} 3$ shows the OVF distribution of this stage and the presence of almost pure inorganic and pure organic particles. This may be the stage where fragments of particles from shattering and particle bouncing are found, with bouncing being a particular issue for viscous particles like these (Virtanen et al., 2010; Dzubay et al., 1976; Jain and Petrucci, 2015; Saukko et al., 2012). Because shattered fragments will not necessarily have the same organic / inorganic ratio as the bulk solution, these particles can have much higher and much lower OVF values. Figure S4 shows an X-ray micrograph of stage-D particles, with arrows pointing to potential fragments from shattering. These small particles are irregularly shaped (compared to the numerous surrounding circular particles) and have extremely high and low OVF values

\subsection{Effect of inorganic and organic assumptions on OVF accuracy}

All data shown above have been obtained with the known compounds being used in calculating OVF values. However, studies of ambient samples often lack prior knowledge of the major inorganic and organic species present within individual particles. Previous studies have utilized this OVF calculation for sea-spray aerosols, and for these samples, sodium chloride and adipic acid, were used as proxies. Sodium chloride was chosen as an inorganic due to its prevalence in ocean water, and adipic acid was chosen because it has an $\mathrm{O}: \mathrm{C}$ ratio of 0.66 , which corresponds to aged organic aerosol species (Jimenez et al., 2009). Figure 8 and Table 3 show the result of this assumption for each system studied here.

The sodium chloride / sucrose system shows the effect of changing only the organic assumption from sucrose to adipic acid. Adipic acid has been used before as a proxy for oxidized organic matter based on its $\mathrm{O}: \mathrm{C}$ ratio (Jimenez et al., 2009). Table 3 shows that the experimental average OVF for each formulation decreased slightly, with the average OVF of the organic rich system decreasing more than the $1: 1$ system. The inorganic-rich system showed very little change in experimental OVF which is expected because the assumed inorganic did not change. The insensitivity of OVF values to the assumed organic has been previously remarked upon using a few other assumed organics as well (Pham et al., 2017).

There is a much more pronounced error introduced by using sodium chloride as a proxy for ammonium sulfate inorganics. Although the sensitivity of OVF to the assumed inorganic increased compared to the assumed organic, the error is accentuated in this specific case. Because $\mathrm{Cl}$ has an absorption edge quite close $(\sim 270 \mathrm{eV})$ to the $\mathrm{C}$-absorption edge, including or excluding $\mathrm{Cl}$ will result in a significant change in how the pre-edge mass absorption coefficient is calculated and can result in up to a $25 \%$ error in OVF. In the case of assuming sodium chloride instead of ammonium sulfate, more of the pre-edge OD is attributed to the increased absorption coefficient and less to the mass (and therefore the thickness) of the inorganic. This effect inflated the OVF of both the $1: 1$ and the inorganic-rich system. The overestimation of OVF was subdued in the inorganic-rich system because the OVF is calculated as a ratio between the organic and total volume: if the organic volume is small to begin with, the ratio will not be as affected by changes in the total volume.

Although OVFs are of interest due to their utility in $\kappa$ Köhler calculations, OMF values are readily obtained and have the benefit of not needing to assume the density of the organic and inorganic components. As far as calculating OMF vs. OVF when the composition is known, there is no difference in the error with respect to the bulk solution values (as seen in Table 2). Table 3 also compares the OMF values obtained using the known organic and inorganic composition with the OMF values obtained from the adipic-acidsodium-chloride assumption. At first glance, the OMF differences between the known and assumed cases do not share the trend seen with OVF values. This is because the error associated with assuming an inorganic and organic composition lies in two places: the calculation of the mass absorption coefficient, and the density. The larger an assumed mass absorption coefficient, the more absorption will be assigned to a specific component. Largely independent from this is the density assumption, which dictates the volume of a specific component. These two values can serve to affect resulting OVF in the same direction together, or can act separately in opposite directions. Because of this, the effect of removing the assumption of density to calculate OMF instead of OVF changes on a case-by-case basis. For any given set of assumptions, however, the OVF and OMF will always differ by a 
Table 3. Experimental and bulk values for organic volume fraction and organic mass fraction under different assumptions about the inorganic and organic component. The difference between OVF values using the known composition vs. using sodium chloride and adipic acid is also shown.

\begin{tabular}{|c|c|c|c|c|c|c|c|}
\hline \multirow[b]{2}{*}{ System } & & \multicolumn{3}{|c|}{ Organic volume fraction } & \multicolumn{3}{|c|}{ Organic mass fraction } \\
\hline & & $\begin{array}{r}\text { Assumed } \\
\text { composition }\end{array}$ & $\begin{array}{r}\text { Known } \\
\text { composition }\end{array}$ & $\begin{array}{r}\text { Percent } \\
\text { difference }\end{array}$ & $\begin{array}{r}\text { Assumed } \\
\text { composition }\end{array}$ & $\begin{array}{r}\text { Known } \\
\text { composition }\end{array}$ & $\begin{array}{r}\text { Percent } \\
\text { difference }\end{array}$ \\
\hline \multirow[t]{3}{*}{ Sodium chloride / sucrose } & Inorganic rich & 0.132 & 0.132 & 0 & 0.087 & 0.100 & 1.3 \\
\hline & $1: 1$ & 0.533 & 0.538 & 0.4 & 0.434 & 0.467 & 3.2 \\
\hline & Organic rich & 0.917 & 0.923 & 0.6 & 0.886 & 0.900 & 1.5 \\
\hline \multirow[t]{3}{*}{ Ammonium sulfate / sucrose } & Inorganic rich & 0.198 & 0.091 & 10.8 & 0.132 & 0.082 & 4.9 \\
\hline & $1: 1$ & 0.723 & 0.571 & 15.2 & 0.589 & 0.542 & 4.7 \\
\hline & Organic rich & 0.931 & 0.926 & 0.5 & 0.899 & 0.917 & 1.8 \\
\hline
\end{tabular}

constant $(C)$ via the following equation:

$C=\frac{\left(f^{\mathrm{I}} \rho^{\mathrm{O}}+f^{\mathrm{O}} \rho^{\mathrm{I}}\right)}{\left(\left(f^{\mathrm{O}}+f^{\mathrm{I}}\right) \rho^{\mathrm{I}}\right)}$

where $f^{x}$ and $\rho^{x}$ represent the mass fraction and density of component $x$, respectively.

The OMF calculations in Table 3 also show that these calculations are more sensitive to the assumptions about the inorganic component than the organic component. The OMF calculations also show that an erroneous mass absorption coefficient assumption will affect the calculation's accuracy, even without the assumption of density. In addition, in order to calculate a mass absorption coefficient, a molecular formula must be assumed. For organic components, these assumptions are often supported by estimates of $\mathrm{O} / \mathrm{C}$ or $\mathrm{N} / \mathrm{C}$ ratios. These constraints, along with the usefulness of the OVF calculation, can make assuming a density worthwhile. The error of using the assumed system of $\mathrm{NaCl}$ and adipic acid (with densities of 2.16 and $1.36 \mathrm{~g} \mathrm{~mL}^{-1}$ ) in the extreme case that the density assumptions are very wrong in opposite directions (say the real composition is $\mathrm{Fe}_{2} \mathrm{O}_{3}$ and pinene with densities of 5.24 and $0.86 \mathrm{~g} \mathrm{~mL}^{-1}$ ) is approximately a factor of 3 .

Note that an appropriate choice for the organic or inorganic proxy for calculation purposes can be guided using peripheral measurements when analyzing ambient samples. Size-resolved composition information (either molecular or elemental) can be used to constrain the identity of the components. Additionally, combining another microscopy technique, which can probe heavier elements, like scanning electron microscopy with energy dispersive X-ray spectroscopy (SEM/EDX), will narrow down the possible inorganics present within individual particles as has been shown previously (Fraund et al., 2017). Also, because the mass absorption coefficient is calculated from the compound's molecular formula, measurements of elemental ratios can serve to improve the OVF value calculation. Because of the erroneous assumption about $\mathrm{Cl}$ in the ammonium sul- fate / sucrose system discussed above, the change in OVF in this case represents one of the larger errors possible.

\section{Conclusions}

The OVF values determined experimentally matched the values from the bulk solution well, when the known inorganic and organic compounds are used. Aerosols that are primarily composed of either inorganic or organic seem to produce the smallest errors. The OVF of organic aerosols can be determined to within $0.8 \%$ under ideal conditions while the OVF of inorganic aerosols can be determined to within about $1 \%$. Additional care must be taken when mixed phase aerosols are present, so that thick inorganic regions do not compromise the OVF calculation, although OVF can still be calculated to within about $4 \%$, even with thick inorganic regions.

The results shown here are most easily attainable after a series of quality control measures have been conducted. Quality control checks for issues including proper alignment, focused images, and accurate particle detection are important. These issues can result in not only a less reliable OVF calculation, but can greatly change the interpretation of an aerosol data set. Most of these issues are best remedied during data collection, though filtering data after the fact can help as well. The results here also highlight the importance of considering how particle generation and collection factor in to the results. It was observed here that particle shattering and impactor bounce may have contributed to the large spread in OVF values in the 1:1 ammonium sulfate / sucrose system.

The calculation of OVF from OD images necessitates some assumptions which should be examined during data analysis. Regions with high OD ( $>1.5$, outside of the linear range of Beer's law) are again best remedied during data collection by avoiding high-OD particles if possible. Although these high-OD regions can be approximated, the quantitative nature of this technique can be compromised. This approximation tends to depress the average OVF when organic coatings are present, and so should be kept in mind when inter- 
preting results. To ensure quantitative OVF calculations with tight distributions, which agree with bulk measurements, it is important to focus on mainly carbonaceous particles (to ensure sufficient carbon signal) or particles with thin enough inorganic inclusions (to reduce regions in which Beer's law is nonlinear). In general, smaller (fine mode) particles will be best suited to this type of calculation. Assumptions about the identity (or at least the molecular formula and density) of the inorganic component can also potentially have a large effect on the calculated OVF. An incorrect assumption can result in an error upwards of $15 \%$. Because most common organic components in aerosols are similar in composition and density, the OVF is much less sensitive to an incorrect assumption here.

Additional spectroscopic images can be used here to great effect. Along with $\mathrm{C}$ K-edge data, imaging particles using the nearby $\mathrm{Cl}, \mathrm{S}, \mathrm{Ca}$, or $\mathrm{K}$ edges can help both better define particle boundaries and improve assumptions about the inorganic component. This, however, comes at the cost of particle population statistics, as more time is spent on fewer particles. Similarly, the identity of the organic component can be better refined by including more energies while taking $\mathrm{C}$-edge data. For example, including an image at $290.1 \mathrm{eV}$ could help remedy the issue mentioned above about carbonate, falsely increasing the amount of organics.

With the proper attention paid to the quality of data, STXM can be used to quantitatively determine the OVF of a set of aerosols to within less than $1 \%$. This method of calculating OVF has previously been used on ambient samples as an indirect measure of biological activity in seawater (Pham et al., 2017). When applying this method to ambient samples, the analyst should note factors that can affect the accuracy of the results. As an example, volatile organics and inorganics (such as ammonium nitrate) will not be accounted for due to evaporation in the vacuum of the STXM chamber. However, even being predicated on assumptions about the inorganic and organic components, the OVF can be quantitatively determined. Because of this, other STXM results, such as the mass fraction of carbon and the absolute mass of carbon (which do not rely on density assumptions), can be determined quantitatively as well. Because STXM offers morphological information along with elemental and molecular composition on a subparticle basis, it can be a powerful technique for analyzing aerosol populations. If care is taken during data collection and analysis, these quantitative results can be used to develop model parameterizations with some confidence regarding the level of associated error.

Data availability. The data set used here is available for download as a .zip file at https://doi.org/10.17605/OSF.IO/27RZX (Fraund, 2019).
Code availability. MatLab code used for the current work is available as a Supplement. A set of semi-regularly updated scripts is also available at https://github.com/MFraund/OrganicVolumeFraction_ StandardAerosols (last access: 8 November 2018).

Supplement. The supplement related to this article is available online at: https://doi.org/10.5194/amt-12-1619-2019-supplement.

Author contributions. MF led data collection, analysis, and writing of the article and oversaw sample preparation. TP did calculations for and prepared the standard solutions and aerosol samples. LY assisted with data analysis and writing. DB assisted with sample preparation and collected STXM data. DQP collected STXM data. RCM conceived the experiment, directed standard and sample preparation, collected STXM data, and administered the project. All authors provided input on the project and edited the manuscript.

Competing interests. The authors declare that they have no conflict of interest.

Acknowledgements. Funding for the data analysis was supported by the US DOE's Atmospheric System Research Program, BER under grant DE-SC0013960. This research used resources of the Advanced Light Source, which is a DOE Office of Science User Facility under contract no. DE-AC02-05CH11231. The authors would also like to acknowledge beamline 5.3.2.2 and its staff: David Shapiro, David Kilcoyne, and Matthew Markus.

Research described in this paper was also performed at the Canadian Light Source, which is supported by the Canada Foundation for Innovation, Natural Sciences and Engineering Research Council of Canada, the University of Saskatchewan, the Government of Saskatchewan, Western Economic Diversification Canada, the National Research Council Canada, and the Canadian Institutes of Health Research. The authors would also like to acknowledge the SM beamline 10ID-1 and its staff: Jian Wang, Yingshen Lu, and Jan Geilhufe.

Edited by: Mingjin Tang

Reviewed by: three anonymous referees

\section{References}

Adachi, K. and Buseck, P. R.: Internally mixed soot, sulfates, and organic matter in aerosol particles from Mexico City, Atmos. Chem. Phys., 8, 6469-6481, https://doi.org/10.5194/acp-8-64692008, 2008.

Altaf, M. B. and Freedman, M. A.: Effect of Drying Rate on Aerosol Particle Morphology, J. Phys. Chem. Lett., 8, 3613-3618, 2017.

Altaf, M. B., Zuend, A., and Freedman, M. A.: Role of nucleation mechanism on the size dependent morphology of organic aerosol, Chem. Commun., 52, 9220-9223, 2016. 
Artaxo, P., Gerab, F., and Rabello, M. L.: Elemental composition of aerosol particles from two atmospheric monitoring stations in the Amazon Basin, Nucl. Instrum. Meth. B, 75, 277-281, 1993.

Asano, H., Aoyama, T., Mizuno, Y., and Shiraishi, Y.: Highly TimeResolved Atmospheric Observations Using a Continuous Fine Particulate Matter and Element Monitor, ACS Earth and Space Chemistry, 1, 580-590, 2017.

Ault, A. P. and Axson, J. L.: Atmospheric Aerosol Chemistry: Spectroscopic and Microscopic Advances, Anal. Chem., 89, 430-452, 2016.

Baumgardner, D., Kok, G., and Raga, G.: Warming of the Arctic lower stratosphere by light absorbing particles, Geophys. Res. Lett., 31, L06117, https://doi.org/10.1029/2003GL018883, 2004.

Baustian, K. J., Cziczo, D. J., Wise, M. E., Pratt, K. A., Kulkarni, G., Hallar, A., and Tolbert, M. A.: Importance of aerosol composition, mixing state, and morphology for heterogeneous ice nucleation: A combined field and laboratory approach, J. Geophys. Res.-Atmos., 117, D06217, https://doi.org/10.1029/2011JD016784, 2012.

Baustian, K. J., Wise, M. E., Jensen, E. J., Schill, G. P., Freedman, M. A., and Tolbert, M. A.: State transformations and ice nucleation in amorphous (semi-)solid organic aerosol, Atmos. Chem. Phys., 13, 5615-5628, https://doi.org/10.5194/acp13-5615-2013, 2013.

Bertram, A. K., Martin, S. T., Hanna, S. J., Smith, M. L., Bodsworth, A., Chen, Q., Kuwata, M., Liu, A., You, Y., and Zorn, S. R.: Predicting the relative humidities of liquid-liquid phase separation, efflorescence, and deliquescence of mixed particles of ammonium sulfate, organic material, and water using the organic-to-sulfate mass ratio of the particle and the oxygen-tocarbon elemental ratio of the organic component, Atmos. Chem. Phys., 11, 10995-11006, https://doi.org/10.5194/acp-11-109952011, 2011.

Beydoun, H., Polen, M., and Sullivan, R. C.: A new multicomponent heterogeneous ice nucleation model and its application to Snomax bacterial particles and a Snomax-illite mineral particle mixture, Atmos. Chem. Phys., 17, 13545-13557, https://doi.org/10.5194/acp-17-13545-2017, 2017.

Bodsworth, A., Zobrist, B., and Bertram, A. K.: Inhibition of efflorescence in mixed organic-inorganic particles at temperatures less than $250 \mathrm{~K}$, Phys. Chem. Chem. Phys., 12, 12259-12266, 2010.

Bones, D. L., Reid, J. P., Lienhard, D. M., and Krieger, U. K.: Comparing the mechanism of water condensation and evaporation in glassy aerosol, P. Natl. Acad. Sci. USA, 109, 11613-11618, 2012.

Bourdelle, F., Benzerara, K., Beyssac, O., Cosmidis, J., Neuville, D. R., Brown, G. E., and Paineau, E.: Quantification of the ferric/ferrous iron ratio in silicates by scanning transmission X-ray microscopy at the Fe L2, 3 edges, Contrib. Mineral. Petr., 166, 423-434, 2013.

Buseck, P. R. and Posfai, M.: Airborne minerals and related aerosol particles: Effects on climate and the environment, P. Natl. Acad. Sci. USA, 96, 3372-3379, 1999.

Canagaratna, M., Jayne, J., Jimenez, J., Allan, J., Alfarra, M., Zhang, Q., Onasch, T., Drewnick, F., Coe, H., and Middlebrook, A.: Chemical and microphysical characterization of ambient aerosols with the aerodyne aerosol mass spectrometer, Mass Spectrom. Rev., 26, 185-222, 2007.
Choi, M. Y. and Chan, C. K.: The effects of organic species on the hygroscopic behaviors of inorganic aerosols, Environ. Sci. Technol., 36, 2422-2428, 2002.

Chow, J. C.: Measurement methods to determine compliance with ambient air quality standards for suspended particles, J. Air Waste Manage., 45, 320-382, 1995.

Cruz, C. N. and Pandis, S. N.: The effect of organic coatings on the cloud condensation nuclei activation of inorganic atmospheric aerosol, J. Geophys. Res.-Atmos., 103, 13111-13123, 1998.

DeMott, P. J., Sassen, K., Poellot, M. R., Baumgardner, D., Rogers, D. C., Brooks, S. D., Prenni, A. J., and Kreidenweis, S. M.: African dust aerosols as atmospheric ice nuclei, Geophys. Res. Lett., 30, 1732, https://doi.org/10.1029/2003GL017410, 2003.

Dudragne, L., Adam, P., and Amouroux, J.: Time-resolved laserinduced breakdown spectroscopy: application for qualitative and quantitative detection of fluorine, chlorine, sulfur, and carbon in air, Appl. Spectrosc., 52, 1321-1327, 1998.

Dzubay, T., Hines, L., and Stevens, R.: Particle bounce errors in cascade impactors, Atmos. Environ., 10, 229-234, 1976.

Fard, M. M., Krieger, U. K., and Peter, T.: Kinetic Limitation to Inorganic Ion Diffusivity and to Coalescence of Inorganic Inclusions in Viscous Liquid-Liquid Phase-Separated Particles, J. Phys. Chem. A, 121, 3613-3618, 2017.

Fraund, M., Pham, D. Q., Bonanno, D., Harder, T. H., Wang, B., Brito, J., de Sá, S. S., Carbone, S., China, S., and Artaxo, P.: Elemental Mixing State of Aerosol Particles Collected in Central Amazonia during GoAmazon2014/15, Atmosphere, 8, 173, https://doi.org/10.3390/atmos8090173, 2017.

Fraund, M.: STXM Standards for OVF Validation, https://doi.org/10.17605/OSF.IO/27RZX, 2019.

Ghosal, S., Weber, P. K., and Laskin, A.: Spatially resolved chemical imaging of individual atmospheric particles using nanoscale imaging mass spectrometry: Insight into particle origin and chemistry, Anal. Meth., 6, 2444-2451, 2014.

Greenwood, N. N. and Earnshaw, A.: Chemistry of the Elements, Elsevier, 2012.

Guizar-Sicairos, M., Thurman, S. T., and Fienup, J. R.: Efficient subpixel image registration algorithms, Opt. Lett., 33, 156-158, 2008.

Hahn, D. W. and Omenetto, N.: Laser-induced breakdown spectroscopy (LIBS), part II: review of instrumental and methodological approaches to material analysis and applications to different fields, Appl. Spectrosc., 66, 347-419, 2012.

Haynes, W. M.: CRC handbook of chemistry and physics, CRC Press, Boca Raton, Florida, 2014.

Healy, R. M., Sciare, J., Poulain, L., Crippa, M., Wiedensohler, A., Prévôt, A. S. H., Baltensperger, U., Sarda-Estève, R., McGuire, M. L., Jeong, C.-H., McGillicuddy, E., O’Connor, I. P., Sodeau, J. R., Evans, G. J., and Wenger, J. C.: Quantitative determination of carbonaceous particle mixing state in Paris using single-particle mass spectrometer and aerosol mass spectrometer measurements, Atmos. Chem. Phys., 13, 9479-9496, https://doi.org/10.5194/acp-13-9479-2013, 2013.

Henke, B. L., Gullikson, E. M., and Davis, J. C.: X-ray interactions: photoabsorption, scattering, transmission, and reflection at $\mathrm{E}=50-30,000 \mathrm{eV}, \mathrm{Z}=1-92$, Atom. Data Nucl. Data, 54, 181342, 1993. 
Jain, S. and Petrucci, G. A.: A new method to measure aerosol particle bounce using a cascade electrical low pressure impactor, Aerosol Sci. Tech., 49, 390-399, 2015.

Jimenez, J., Canagaratna, M., Donahue, N., Prevot, A., Zhang, Q., Kroll, J. H., DeCarlo, P. F., Allan, J. D., Coe, H., and Ng, N.: Evolution of organic aerosols in the atmosphere, Science, 326, 1525-1529, 2009.

Karagulian, F., Lea, A. S., Dilbeck, C. W., and Finlayson-Pitts, B. J.: A new mechanism for ozonolysis of unsaturated organics on solids: phosphocholines on $\mathrm{NaCl}$ as a model for sea salt particles, Phys. Chem. Chem. Phys., 10, 528-541, 2008.

Karanasiou, A., Minguillón, M. C., Viana, M., Alastuey, A., Putaud, J.-P., Maenhaut, W., Panteliadis, P., Mocnik, G., Favez, O., and Kuhlbusch, T. A. J.: Thermal-optical analysis for the measurement of elemental carbon (EC) and organic carbon (OC) in ambient air a literature review, Atmos. Meas. Tech. Discuss., 8, 96499712, https://doi.org/10.5194/amtd-8-9649-2015, 2015.

Kilcoyne, A., Tyliszczak, T., Steele, W., Fakra, S., Hitchcock, P., Franck, K., Anderson, E., Harteneck, B., Rightor, E., and Mitchell, G.: Interferometer-controlled scanning transmission Xray microscopes at the Advanced Light Source, J. Synchrotron. Radiat., 10, 125-136, 2003.

Kwamena, N.-O., Buajarern, J., and Reid, J.: Equilibrium morphology of mixed organic/inorganic/aqueous aerosol droplets: Investigating the effect of relative humidity and surfactants, J. Phys. Chem. A, 114, 5787-5795, 2010.

Laskin, A., Cowin, J. P., and Iedema, M. J.: Analysis of individual environmental particles using modern methods of electron microscopy and X-ray microanalysis, J. Electron Spectrosc., 150, 260-274, 2006.

Li, W., Sun, J., Xu, L., Shi, Z., Riemer, N., Sun, Y., Fu, P., Zhang, J., Lin, Y., and Wang, X.: A conceptual framework for mixing structures in individual aerosol particles, J. Geophys. Res.-Atmos., 121, 13784-13798, https://doi.org/10.1002/2016JD025252, 2016.

Li, W., Xu, L., Liu, X., Zhang, J., Lin, Y., Yao, X., Gao, H., Zhang, D., Chen, J., and Wang, W.: Air pollutionaerosol interactions produce more bioavailable iron for ocean ecosystems, Science Advances, 3, e1601749m https://doi.org/10.1126/sciadv.1601749, 2017.

Maria, S. F., Russell, L. M., Gilles, M. K., and Myneni, S. C.: Organic aerosol growth mechanisms and their climate-forcing implications, Science, 306, 1921-1924, 2004.

Menzel, N., Schramel, P., and Wittmaack, K.: Elemental composition of aerosol particulate matter collected on membrane filters: A comparison of results by PIXE and ICP-AES, Nucl. Instrum. Meth. B, 189, 94-99, 2002.

Moffet, R. C. and Prather, K. A.: Extending ATOFMS measurements to include refractive index and density, Anal. Chem., 77, 6535-6541, 2005.

Moffet, R. C., Henn, T., Laskin, A., and Gilles, M. K.: Automated Chemical Analysis of Internally Mixed Aerosol Particles Using X-ray Spectromicroscopy at the Carbon K-Edge, Anal. Chem., 82, 7906-7914, 2010.

Moffet, Ryan C., Alexei V. Tivanski, and Mary K. Gilles. Scanning transmission X-ray microscopy: Applications in atmospheric aerosol research. No. LBNL-4245E. Lawrence Berkeley National Lab.(LBNL), Berkeley, CA (United States), 2011.
Moffet, R. C., O’Brien, R. E., Alpert, P. A., Kelly, S. T., Pham, D. Q., Gilles, M. K., Knopf, D. A., and Laskin, A.: Morphology and mixing of black carbon particles collected in central California during the CARES field study, Atmos. Chem. Phys., 16, 1451514525, https://doi.org/10.5194/acp-16-14515-2016, 2016.

Möhler, O., Benz, S., Saathoff, H., Schnaiter, M., Wagner, R., Schneider, J., Walter, S., Ebert, V., and Wagner, S.: The effect of organic coating on the heterogeneous ice nucleation efficiency of mineral dust aerosols, Environ. Res. Lett., 3, 025007, https://doi.org/10.1088/1748-9326/3/2/025007, 2008.

Mouri, H. and Okada, K.: Shattering and modification of sea-salt particles in the marine atmosphere, Geophys. Res. Lett., 20, 49$52,1993$.

Ng, N. L., Herndon, S. C., Trimborn, A., Canagaratna, M. R., Croteau, P., Onasch, T. B., Sueper, D., Worsnop, D. R., Zhang, Q., and Sun, Y.: An Aerosol Chemical Speciation Monitor (ACSM) for routine monitoring of the composition and mass concentrations of ambient aerosol, Aerosol Sci. Tech., 45, 780 794, 2011.

O’Brien, R. E., Wang, B., Laskin, A., Riemer, N., West, M., Zhang, Q., Sun, Y., Yu, X. Y., Alpert, P., and Knopf, D. A.: Chemical imaging of ambient aerosol particles: Observational constraints on mixing state parameterization, J. Geophys. Res.-Atmos., 120, 9591-9605, 2015.

Otsu, N.: A threshold selection method from gray-level histograms, Automatica, 11, 23-27, 1975.

Petters, M. D. and Kreidenweis, S. M.: A single parameter representation of hygroscopic growth and cloud condensation nucleus activity, Atmos. Chem. Phys., 7, 1961-1971, https://doi.org/10.5194/acp-7-1961-2007, 2007.

Pham, D. Q., O'Brien, R., Fraund, M., Bonanno, D., Laskina, O., Beall, C., Moore, K. A., Forestieri, S., Wang, X., and Lee, C.: Biological Impacts on Carbon Speciation and Morphology of Sea Spray Aerosol, ACS Earth and Space Chemistry, 1, 551-561, 2017.

Piens, D. S., Kelly, S. T., Harder, T. H., Petters, M. D., O’Brien, R. E., Wang, B., Teske, K., Dowell, P., Laskin, A., and Gilles, M. K.: Measuring mass-based hygroscopicity of atmospheric particles through in situ imaging, Environ. Sci. Technol., 50, 5172-5180, 2016.

Pöschl, U.: Atmospheric aerosols: composition, transformation, climate and health effects, Angew. Chem. Int. Edit., 44, 7520-7540, 2005.

Pöschl, U., Martin, S., Sinha, B., Chen, Q., Gunthe, S., Huffman, J., Borrmann, S., Farmer, D., Garland, R., and Helas, G.: Rainforest aerosols as biogenic nuclei of clouds and precipitation in the Amazon, Science, 329, 1513-1516, 2010.

Pósfai, M., Xu, H., Anderson, J. R., and Buseck, P. R.: Wet and dry sizes of atmospheric aerosol particles: An AFM-TEM Study, Geophys. Res. Lett., 25, 1907-1910, 1998.

Raatikainen, T., Brus, D., Hyvärinen, A.-P., Svensson, J., Asmi, E., and Lihavainen, H.: Black carbon concentrations and mixing state in the Finnish Arctic, Atmos. Chem. Phys., 15, 1005710070, https://doi.org/10.5194/acp-15-10057-2015, 2015.

Redoglio, D. A., Palazzo, N., Migliorini, F., Dondè, R., and De Iuliis, S.: Laser-Induced Breakdown Spectroscopy Analysis of Lead Aerosol in Nitrogen and Air Atmosphere, Appl. Spectrosc., 72, 584-590, 2018. 
Reinhard, E., Heidrich, W., Debevec, P., Pattanaik, S., Ward, G., and Myszkowski, K.: High dynamic range imaging: acquisition, display, and image-based lighting, 2nd ed., Morgan Kaufmann Publishers Inc., San Francisco, CA, ISBN 978-0-12-374914-7, 2010.

Russell, L. M., Maria, S. F., and Myneni, S. C.: Mapping organic coatings on atmospheric particles, Geophys. Res. Lett., 29, 261-26-4, https://doi.org/10.1029/2002GL014874, 2002.

Saukko, E., Kuuluvainen, H., and Virtanen, A.: A method to resolve the phase state of aerosol particles, Atmos. Meas. Tech., 5, 259265, https://doi.org/10.5194/amt-5-259-2012, 2012.

Schwarz, J., Gao, R., Fahey, D., Thomson, D., Watts, L., Wilson, J., Reeves, J., Darbeheshti, M., Baumgardner, D., and Kok, G.: Single-particle measurements of midlatitude black carbon and light-scattering aerosols from the boundary layer to the lower stratosphere, J. Geophys. Res.-Atmos., 111, D16207, https://doi.org/10.1029/2006JD007076, 2006.

Seinfeld, J. H. and Pandis, S. N.: Atmospheric chemistry and physics: from air pollution to climate change, John Wiley \& Sons, Hoboken, New Jersey, ISBN 978-1-118-94740-1, 2006.

Shiraiwa, M., Zuend, A., Bertram, A. K., and Seinfeld, J. H.: Gasparticle partitioning of atmospheric aerosols: interplay of physical state, non-ideal mixing and morphology, Phys. Chem. Chem. Phys., 15, 11441-11453, 2013.

Skoog, D. A., Holler, F. J., and Crouch, S. R.: Principles of instrumental analysis, Thomson Brooks/Cole, 2007.

Spencer, M. T. and Prather, K. A.: Using ATOFMS to determine OC/EC mass fractions in particles, Aerosol Sci. Tech., 40, 585594, 2006.

Stocker, T., Qin, D., Plattner, G., Tignor, M., Allen, S., Boschung, J., Nauels, A., Xia, Y., Bex, V., and Midgley, P.: Contribution of Working Group I to the Fifth Assessment Report of the Intergovernmental Panel on Climate Change, Climate Change, 2013.

Tong, H.-J., Reid, J. P., Bones, D. L., Luo, B. P., and Krieger, U. K.: Measurements of the timescales for the mass transfer of water in glassy aerosol at low relative humidity and ambient temperature, Atmos. Chem. Phys., 11, 4739-4754, https://doi.org/10.5194/acp-11-4739-2011, 2011.
Veghte, D. P., Altaf, M. B., and Freedman, M. A.: Size dependence of the structure of organic aerosol, J. Am. Chem. Soc., 135, 16046-16049, 2013.

Villeneuve, P. J., Goldberg, M. S., Krewski, D., Burnett, R. T., and Chen, Y.: Fine particulate air pollution and all-cause mortality within the Harvard Six-Cities Study: Variations in risk by period of exposure, Ann. Epidemiol., 12, 568-576, 2002.

Virtanen, A., Joutsensaari, J., Koop, T., Kannosto, J., Yli-Pirilä, P., Leskinen, J., Mäkelä, J. M., Holopainen, J. K., Pöschl, U., and Kulmala, M.: An amorphous solid state of biogenic secondary organic aerosol particles, Nature, 467, 824-827, https://doi.org/10.1038/nature09455, 2010.

Warwick, T., Ade, H., Kilcoyne, D., Kritscher, M., Tylisczcak, T., Fakra, S., Hitchcock, A., Hitchcock, P., and Padmore, H.: A new bend-magnet beamline for scanning transmission X-ray microscopy at the Advanced Light Source, J. Synchrotron Radiat., 9, 254-257, 2002.

Wen, X.-D., Löble, M. W., Batista, E. R., Bauer, E., Boland, K. S., Burrell, A. K., Conradson, S. D., Daly, S. R., Kozimor, S. A., and Minasian, S. G.: Electronic structure and O K-edge XAS spectroscopy of U3O8, J. Electron. Spectrosc., 194, 81-87, 2014

Worsnop, D., Morris, J., Shi, Q., Davidovits, P., and Kolb, C.: A chemical kinetic model for reactive transformations of aerosol particles, Geophys. Res. Lett., 29, 57-1-57-4, https://doi.org/10.1029/2002GL015542, 2002.

Zelenyuk, A. and Imre, D.: Single particle laser ablation time-offlight mass spectrometer: an introduction to SPLAT, Aerosol Sci. Tech., 39, 554-568, 2005. 